HUMANAS E SOCIAIS

V.9 • N.2 • 2021 • Fluxo Contínuo

ISSN Digital: 2316-3801

ISSN Impresso: 2316-3348

DOI: 10.17564/2316-3801.2021v9n2p342-355

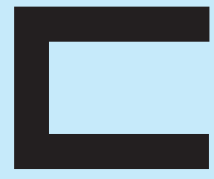

开 $N$ 开

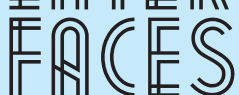

CIENTÍFICAS

\section{DISPUTA ELEITORAL EM TERRAS CAPIXABAS: O PARTIDO DA MULHER BRASILEIRA NAS ELEIÇÕES MUNICIPAIS DE 2016}

ELECTORAL DISPUTE IN LANDS CAPIXABAS: THE PARTIDO DA MULHER BRASILEERA IN THE MUNICIPAL ELECTIONS OF 2016

DISPUTAS ELECTORALESENTIERRASCAPIXABAS: EL PARTIDODA MULHER BRASILEIRA EN LASELECCIONES MUNICIPALES DE २०१६

\section{RESUMO}

Sabemos que no mundo da política o predomínio do homem é absoluto. 0 Partido da Mulher Brasileira surge para tentar inserir as mulheres nesse mundo e em 2016 esse partido participou pela primeira vez de um pleito eleitoral. 0 objetivo deste artigo foi analisar o perfil sociopolítico dos candidatos do Partido da Mulher Brasileira para pensar a inserção da mulher no mundo da política capixaba. 0 recorte temporal foi o ano de 2016 e a técnica de coleta e a análise dos dados foram baseadas nos principais métodos de pesquisa nas Ciências Sociais. Os resultados revelaram a existência de um perfil sociopolítico compartilhado pelos candidatos a vereança do Partido da Mulher Brasileira em terras capixabas.

\section{PALAVRAS-CHAVE}

Partido da Mulher Brasileira. Eleições Municipais. Perfil Sociopolítico. Vereadores.
Necilene Almeida de Freitas ${ }^{1}$ Erika de Oliveira Cavalcanti ${ }^{2}$ Riberti de Almeida Felisbino ${ }^{3}$ 


\section{ABSTRACT}

In the world of politics, the dominance of man is absolute. The Partido da Mulher Brasileira is born to try to insert women in this world and in 2016 the party participated for the first time in an electoral dispute. The purpose of this paper is to know the socioecopolitical profile of the candidates of the Partido da Mulher Brasileira to think about the insertion of women in the world of politics in the state of Espírito Santo. 2016 was the year of data collection and the technique and analysis were based on research methods in the Social Sciences. The results revealed the existence of a sociopolitical profile shared by the candidates for the Partido da Mulher Brasileira in lands capixabas.

\section{KEYWORDS}

Partido da Mulher Brasileira. Local Elections. Sociecopolitical Profile. Council-Man.

\section{RESUMEN}

En el mundo de la política, el dominio del hombre es absoluto. El Partido da Mulher Brasileira surgió para tratar de insertar a las mujeres en este mundo y en 2016 el partido participó por primera vez en una elección. El objetivo de este artículo fue analizar el perfil sociopolítico de las candidatas del Partido da Mulher Brasileira para pensar en la inserción de las mujeres en el mundo de la política en Espírito Santo. El corte de tiempo fue el año 2016 y la técnica de recolección y análisis de datos se basó en los principales métodos de investigación de las Ciencias Sociales. Los resultados revelaron la existencia de un perfil sociopolítico compartido por las candidatas del Partido da Mulher Brasileira en tierras capixabas.

\section{PALAVRAS-CHAVE}

Partido da Mulher Brasileira. Elecciones Municipales. Perfil sociopolítico. Concejales. 


\section{INTRODUÇ̃̃̃O}

Na moderna democracia, entre os caminhos oferecidos às mulheres, o partido se destaca como uma das instituições promotoras da inserção delas na política. Em 2015, o Partido da Mulher Brasileira (PMB) surge com a proposta de promover essa inserção. Embora essa legenda partidária queira empoderar as mulheres para vida política, o partido não conseguiu, no pleito de 2016, estimular a participação delas. Dos 1.688 candidatos aptos a disputarem as eleições legislativas de 2016, 1.052 eram homens e 636 mulheres. Do total, 165 homens conseguiram o sucesso almejado, enquanto apenas 51 mulheres obtiveram o êxito. Quando olhamos para o Estado do Espírito Santo, mais da metade dos candidatos que representaram a legenda partidária nas eleições municipais de 2016 foram mulheres $(51,6 \%)$ e somente duas saíram do pleito vitoriosas.

Este artigo tem o propósito de analisar o perfil sociopolítico dos candidatos do PMB para pensar a inserção da mulher no mundo da política capixaba. 0 recorte temporal foi o ano de 2016 e a técnica de coleta e a análise dos dados foram baseadas nos principais métodos de pesquisa nas Ciências Sociais. A principal indagação que orienta as discussões do artigo é: Quem são essas pessoas que querem defender as causas das mulheres e buscam um lugar no diminuto grupo político local? 0 artigo procura elucidar, empiricamente, estas indagações para pensar o PMB e as eleições municipais de 2016 no Estado do Espírito Santo. Os dados foram coletados do site Divulgação de Candidaturas e Contas Eleitorais, vinculado ao Tribunal Superior Eleitoral (TSE), permitindo traçar sociologicamente a imagem do futuro parlamentar municipal representante do PMB nos municípios capixabas.

Além desta Introdução e das Considerações Finais, em seguida, i) abordamos brevemente o caminho histórico da conquista do sufrágio feminino; ii) exploramos a incorporação da Lei de Cotas no arranjo normativo e iii) examinamos o PMB nas eleições municipais capixabas de 2016.

\section{VOTAR E SEREM VOTADA, O SUFRÁGIO FEMININO}

A concessão do direito ao voto e a participação em disputas eleitorais garantiram as mulheres a tão sonhada cidadania política, contudo, inserir as mulheres no ambiente político não foi tarefa fácil. Em momento algum os primeiros constituintes se preocuparam em abolir as leis discriminatórias e revestir as mulheres de igual status sociopolítico (VERUCCI, 1999). Entretanto, o desejo de votar e participar politicamente aumentavam cada vez mais entre as mulheres, reforçando o ideal que desafiava os valores até então estabelecidos.

Inicialmente, o direito ao voto e a participação em disputas eleitorais foram conquistados no ano de 1927 no Estado do Rio Grande do Norte e inserido nas Disposições Gerais da Lei Estadual $n^{\circ}$ 660/1927, art. 77 que assim passou a dispôs: "No Rio Grande do Norte, poderão votar e ser votados, sem distinção de sexo, todos os cidadãos que reunirem as condições exigidas por esta lei”.

Após a concessão do direito ao voto, Celina Guimarães Viana foi a primeira potiguar a fazer o alistamento eleitoral. 0 Rio Grande do Norte também foi o precursor na eleição da primeira mulher a 
ocupar um cargo público na América Latina. No ano de 1928, Alzira Soriano foi eleita com $60 \%$ dos votos para assumir a prefeitura de Lages/RN. Sua posse ocorreu em $1^{\circ}$ de janeiro de 1929 e durou apenas dois anos sendo interrompida em virtude da revolução de 1930 (CEVA; SCHUMAHER, 2015).

Apesar do direito ao voto ter sido garantido às potiguares no ano de 1927, no restante do país esse direito somente seria concedido às demais mulheres cinco anos mais tarde. Durante esse insterstício temporal inúmeras reivindicações continuaram sendo realizadas em todos os outros Estados brasileiros. A garantia do voto conquistada em outros países, estimulava cada vez mais as brasileiras: as australianas comemoraram essa vitória em 1902; logo em seguida foi a vez das finlandesas, em 1906; seguidas pelas norueguesas em 1913; em 1915 pelas islândesas e dinamarquesas; em 1917 as holandesas e russas; em 1918 foram contempladas as inglesas, as alemãs, as canadenses e as polonesas. Já nos Estados Unidos, as mulheres conquistaram o sufrágio em 1919, porém, a ratificação ocorreu apenas em 1920 (CEVA; SCHUMAHER, 2015).

Finalmente, no dia 24 de fevereiro de 1932, foi a vez das brasileiras alcançarem a tão sonhada oportunidade de votar e serem votadas. 0 voto feminino foi introduzido no Código Eleitoral Provisório por meio da assinatura do Decreto $n^{0} 21.076 / 1932$, pelo presidente Getúlio Vargas, assegurando às mulheres o direito de votar e de serem votadas, nos seguintes termos:

DECRETO n 21.076, DE 24 DE FEVEREIRO DE 1932

Art. $2^{\circ}$ É eleitor o cidadão maior de 21 anos, sem distinção de sexo, alistado na forma deste Código. (Grifo nosso).

TÍTULO II

Das condições de elegibilidade

Art. 59. São condições de elegibilidade:

$\left.1^{\circ}\right)$ ser eleitor;

$2^{\circ}$ ) ter mais de quatro anos de cidadania.

A aquisição desse direito foi consolidada em bases constitucionais apenas no ano de 1934. Em 1964 o voto passou a ser obrigatório para homens e mulheres alfabetizados e somente em 1985 esse direito se estendeu aos analfabetos de ambos os sexos. Após a instituição da Constituição Federal de 1988, o sufrágio universal e o voto direto e secreto, com igual valor para todos, passou a ser considerado exercício da soberania popular, conforme disposto no art. 14, capítulo IV, da Constituição Federal.

\section{A LEI DE COTAS NO ORDENAMENTO LEGAL}

O sistema de cotas para candidatura partidária feminina foi instituído, inicialmente, por meio da Lei n 9.100/1995, que estabelecia normas para as eleições municipais e assim dispunha em seu art. 11, § 30: "vinte por cento, no mínimo, das vagas de cada partido ou coligação deveriam ser preenchidas por candidaturas de mulheres". A reserva de $20 \%$ foi considerada inconstitucional, vez que 
vivemos em um país que defende a igualdade entre os sexos, tal inconstitucionalidade resultou na alteração da Lei n⿳0 9.100/1995 e a política de cotas passou a ser regulamentada pela Lei Federal n⿳0 9.504/1997 que estabelece normas para as eleições, nos seguintes termos:

Lei $n^{\circ} 9.504$

Estabelece normas para as eleições de outubro de 1998 e dá outras providências.

Art. 10. Cada partido poderá registrar candidatos para a Câmara dos Deputados, Câmara Legislativa, Assembleias Legislativas e Câmaras Municipais, até cento e cinquenta por cento do número de lugares a preencher.

$\S 3^{\circ}$ Do número de vagas resultante das regras previstas neste artigo, cada partido ou coligação deverá reservar o mínimo de trinta por cento e o máximo de setenta por cento para candidaturas de cada sexo. (Grifo nosso).

A introdução da Lei de Cotas no Brasil não mais prevê apenas a "reserva mínima" de 30\% das vagas para candidatura de cada sexo, mas sim, a obrigação de se preencher tal reserva, por meio da promulgação da Lei n 12.034/2009 que alterou a Lei n 9.096/1995 (Lei dos Partidos Políticos), bem como o $\S 3^{\circ}$, art. 10 da mencionada Lei no 9.504/1997, que estabelece normas para as eleições:

Lei n. ${ }^{0} 12.034 / 2009$

$\S 3^{\circ}$ Do número de vagas resultante das reservas previstas neste artigo, cada partido ou coligação preencherá o mínimo de 30,0\% e o máximo de 70,0\% para candidaturas de cada sexo". (Grifo nosso).

Todavia, questiona-se a eficiência dessa lei, pois, apesar de o novo dispositivo prever a obrigação do preenchimento formal dessa reserva legal, não existe o comprometimento das legendas partidárias de preencherem as vagas com a obrigação de resultados, assim, muitas vezes, as mutheres exercem apenas o papel de "laranjas" nos partidos. Percebe-se que a Lei de Cotas não logrou êxito na promoção da igualdade e inclusão política, afinal, de nada adianta reservar vagas e não incentivar a militância feminina.

0 processo de inserção da mulher na política perpassa por questões como a sobrecarga de tarefas domésticas, o desinteresse e falta de estrutura das legendas partidárias, a ineficiência dentro do atual sistema brasileiro de cotas nas listas de candidaturas, a baixa alocação de recursos nas campanhas das mulheres, a falta de punição aos partidos que não cumprem a legislação, a falta de formação e de campanhas de conscientização. Esse contexto nos leva a discutir sobre o impacto e a extensão da eficácia ou ineficácia da Lei de Cotas no universo da representação feminina. A desigualdade entre os sexos na política é tão grande que coloca o Brasil na $132^{a}$ posição do ranking de representação feminina no interior do Congresso Nacional (INTER-PARLIAMENTARY UNION, on-line). 


\section{PARTIDO DA MULHER BRASILEIRA NAS ELEIC̄ÕES CAPIXABAS DE 2016}

Vem sendo discutida, tendo em vista que a representação política feminina com mais frequência nas últimas décadas, surge em 2008 o projeto político que sete anos mais tarde se transformaria no PMB, organizado em conformidade com a Lei no 9.096/1995 e aprovada em 29 de setembro de 2015, com o número eleitoral 35, sob a direção de Suêd Haidar.

Logo após a sua aprovação, em janeiro de 2016 o PMB ascendeu rapidamente na Câmara dos Deputados em razão da migração de 21 parlamentares que passaram a defender os seus ideais, entretanto, abruptamente o partido ficou sem representatividade ao ser abandonado por todos os congressistas. Contudo, esse fato trágico em nada desestruturou a legenda que seguiu firmemente em meio às críticas, apresentando como principal pilar o interesse pela valorização social, moral, profissional e política da mulher. Essa legenda partidária nasce com a proposta de promover a inserção da mulher nas esferas de poderes, proporcionando voz a esse universo e dialogando com as suas necessidades de se expressar em um cenário que nunca contou com a sua efetiva participação.

Apesar de essa legenda ser extremamente nova nas disputas eleitorais e não oferecer fontes suficientes para a realização de pesquisas, nosso objetivo foi levantar algumas informações sociopolíticas sobre os candidatos à vereança filiados ao PMB no Estado do Espírito Santo. As principais indagações que conduziram as atividades empíricas foram: i) Quem são essas pessoas que querem defender as causas das mulheres e buscam um lugar no diminuto grupo político local? ii) Qual o perfil sociopolítico delas? Para responder as indagações levantadas, os dados foram coletados do site Divulgação de Candidaturas e Contas Eleitorais do TSE, onde foram levantadas informações sociais e políticas. Assim foi traçada sociologicamente a imagem do futuro parlamentar municipal representante do PMB nos municípios capixabas.

É importante destacar, que as variáveis aqui analisadas são relevantes para o estudo da elite política local, pois elas, de acordo com Perissinotto (2012, p. 191), “[...] definem a visão de mundo dos seus membros, suas intenções e, por conseguinte, contribuem para definir o conteúdo substantivo de suas decisões". Assim a análise da caracterização das pessoas pode ser feita a partir de seus atributos que permeiam a vida social. Esses atributos podem variar de sociedade para sociedade, mas, segundo Keller (1967), eles podem ser naturais e conquistados.

Segundo a autora, os atributos naturais dizem respeito às características que distinguem os indivíduos, que são, por exemplo, o sexo, idade, cor da pele, cor dos olhos, a estatura etc. Já os atributos conquistados são obtidos pelos indivíduos ao longo das suas vidas, que são, por exemplo, a religião, escolaridade, ocupação, estado civil, ascensão social, a renda etc.

Ao analisarmos o perfil social da classe política a primeira constatação que salta aos olhos do observador é o sexo dos candidatos. Embora a legenda partidária tenha por objetivo alargar o espaço das mulheres na esfera política, podemos ver na matriz abaixo que elas estão disputando, de forma acirrada, espaços com os homens, em um universo de 97 candidatos, 51,6\% foram candidaturas femininas, em face das candidaturas masculinas que alcançaram o percentual de $48,4 \%$. 
Tabela 1 - Distribuição do sexo nas eleições municipais Espírito Santo, 2016

\begin{tabular}{cc}
\hline Sexo & \\
\hline Homem & $48,4(47)$ \\
\hline Mulher & $51,6(50)$ \\
\hline TOTAL & $100,0(97)$ \\
\hline
\end{tabular}

Nota: * (N) Valor absoluto referente ao percentual.

Fonte: Elaboração própria a partir dos dados disponíveis em Divulgação de Candidaturas e Contas Eleitorais do TSE.

Apesar dos resultados da pesquisa sobre o perfil sociopolítico dos candidatos eleitos e não eleitos à vereança do PMB capixaba nas eleições de 2016, apresentarem um nível diferenciado de participação das mulheres, a legenda teve quase metade do quadro de candidatos preenchido pelos homens. 0 dado é relevante, pois, aponta o quanto eles se sentem à vontade no interior desse partido. Mesmo sendo a legenda intitulada "da Mulher Brasileira", os homens não se intimidaram, como se depreende das respostas dos interlocutores ao serem questionados sobre o motivo pelo qual se filiaram ao PMB, sendo que, atualmente existem outras 33 legendas partidárias registradas no Tribunal Superior Eleitoral:

Eu estava no PSB (partido do Casagrande). Na ocasião da eleição em 2015 eu achei meIhor sair e ir para uma legenda onde não tivesse ninguém forte, porque não dava pra ficar no PSB com o [...], porque o [...] era forte, ele teve 4.000 votos em 2012, sendo o mais votado do município de Cariacica, eu teria dificuldades para me eleger, por isso resolvi procurar uma legenda na qual eu fosse o mais forte, a regra é avançar, é desbravar. Eu fui o primeiro vereador no ES a se filiar ao PMB em 9/12/2014, logo em seguida veio o Deputado Amaro Neto, mas não permaneceu, indo para o SOLIDARIEDADE que era mais forte nacionalmente, com nome mais forte e mais recurso financeiro (E4).

A bandeira da inclusão da mulher, que para mim é um vulnerável constitucional me seduziu, enquanto cidadão e advogado, mas vejo que o partido deixa muito a desejar nas políticas públicas para mulheres (E5).

A atitude dos respondentes revela a naturalidade masculina para lidar com questões políticas. Na fala "[...] a regra é avançar, é desbravar" (E4), percebe-se o empoderamento concedido aos homens pela cultura, bem como pelo sistema ao longo dos anos.

0 exame da distribuição etária, mostrado na Tabela 2 , informa que os homens estão concentrados nas faixas de 40 a 49 anos (60,0\%) e de 50 a 59 anos (50,0\%), enquanto as mulheres estão reunidas nas faixas de 30 a 39 anos (60,9\%), de 40 a 49 anos (40,0\%) e de 50 a 59 anos (50,0\%). No geral, ambos os sexos estão representados em todas as faixas etárias. A maioria dos candidatos que representaram o PMB, em sua primeira eleição, está inserida na faixa etária dos 30 aos 59 anos, faixa de idade que traz consigo um conjunto de conhecimentos das necessidades que tanto desejam a população. 
Tabela 2 - Distribuição da faixa etária, segundo sexo nas eleições municipais Espírito Santo, 2016

$\%(\mathrm{~N}) *$

\begin{tabular}{|c|c|c|c|}
\hline \multirow{2}{*}{ Faixa etária } & \multicolumn{2}{|c|}{ Sexo } & \multirow{2}{*}{ TOTAL } \\
\hline & Homem & Mulher & \\
\hline Até 29 anos & $33,3(4)$ & $66,7(8)$ & $100,0(12)$ \\
\hline De 30 a 39 anos & $39,1(9)$ & $60,9(14)$ & $100,0(23)$ \\
\hline De 40 a 49 anos & $60,0(18)$ & 40,0 (12) & $100,0(30)$ \\
\hline De 50 a 59 anos & $50,0(12)$ & $50,0(12)$ & $100,0(24)$ \\
\hline 60 anos ou mais & $50,0(4)$ & $50,0(4)$ & 100,0 (8) \\
\hline
\end{tabular}

Nota: * $(\mathrm{N})$ Valor absoluto referente ao percentual.

Fonte: Elaboração própria a partir dos dados disponíveis em Divulgação de Candidaturas e Contas Eleitorais do TSE.

A participação feminina na política aponta para o amadurecimento do sistema democrático (MOISES; SANCHES, 2014; FREITAS; FELISBINO; SANTIAGO, 2018). A Tabela 2 registra que o PMB contou com um bom percentual de candidatas inseridas em uma faixa etária mais nova (de 30 a 39 anos, $60,9 \%)$. Entendemos que esse fato é um reflexo das lutas femininas travadas ao longo da história, lutas que têm incentivado uma nova geração de mulheres a participarem da vida política.

A análise da distribuição do estado civil, observado na Tabela 3, o grupo que representou o partido na primeira eleição capixaba foi composto majoritariamente por candidatos solteiros (40,0\% homens e $60,0 \%$ mulheres) e casados (56,8\% homens e 43,2\% mulheres). É importante destacar que os percentuais relacionados às mulheres podem indicar uma conscientização delas de que é necessário participar das atividades políticas do seu município. Ainda com relação ao estado civil, também a podemos ver na Tabela 3 que os divorciados e os viúvos formaram o quadro de candidatos do PMB.

Tabela 3 - Distribuição do estado civil, segundo sexo nas eleições municipais

Espírito Santo, 2016

$\%(\mathrm{~N}) *$

\begin{tabular}{c|ccc}
\hline \multirow{2}{*}{ Estado civil } & \multicolumn{2}{|c}{ Sexo } & \multirow{2}{*}{ TOTAL } \\
\cline { 2 - 3 } & Homem & Mulher & \\
\hline Solteiro & $40,0(14)$ & $60,0(21)$ & $100,0(35)$ \\
Casado & $56,8(25)$ & $43,2(19)$ & $100,0(44)$ \\
Divorciado & $50,0(7)$ & $50,0(7)$ & $100,00(14)$ \\
\hline
\end{tabular}




\begin{tabular}{c|cccc}
\hline \multicolumn{2}{c}{ Estado civil } & \multicolumn{2}{c}{ Sexo } & \multirow{2}{*}{ (N)* } \\
\cline { 2 - 4 } & Homem & Mulher & TOTAL \\
\hline Viúvo & $25,0(1)$ & $75,0(3)$ & & $100,0(4)$ \\
\hline
\end{tabular}

Nota: * (N) Valor absoluto referente ao percentual.

Fonte: Elaboração própria a partir dos dados disponíveis em Divulgação de Candidaturas e Contas Eleitorais do TSE.

O exame da distribuição do grau de instrução, exibido na Tabela 4, notamos que a escolaridade dos candidatos se apresentou bastante diversificada, onde os homens e as mulheres estão representados em todos os grupos escolares. Tanto no $1^{\circ} \mathrm{grau}$ (Completo/Incompleto) quanto no $2^{\circ} \mathrm{grau}$ (Completo/Incompleto), ambos os sexos estão igualmente representados. Na outra ponta, quando olhamos para o $3^{\circ} \mathrm{grau}$ (Completo/Incompleto), as mulheres são mais escolarizadas que os homens.

Tabela 4 - Distribuição da escolaridade, segundo sexo nas eleições municipais Espírito Santo, 2016

\begin{tabular}{|c|c|c|c|}
\hline & & & $\%(N) *$ \\
\hline \multirow{2}{*}{ Escolaridade } & \multicolumn{2}{|c|}{ Sexo } & \multirow{2}{*}{ TOTAL } \\
\hline & Homem & Mulher & \\
\hline $1^{\circ} \mathrm{Grau}$ Completo & $44,4(4)$ & $55,6(5)$ & 100,0 (9) \\
\hline $1^{\circ} \mathrm{Grau}$ Incompleto & $52,6(10)$ & 47,4 (9) & 100,0 (19) \\
\hline $2^{\circ} \mathrm{Grau}$ Completo & $51,4(19)$ & $48,6(18)$ & $100,0(37)$ \\
\hline $2^{\circ} \mathrm{Grau}$ Incompleto & $40,0(2)$ & $60,0(3)$ & $100,0(5)$ \\
\hline $3^{\circ} \mathrm{Grau}$ Completo & $45,0(9)$ & $55,0(11)$ & $100,0(20)$ \\
\hline $3^{\circ} \mathrm{Grau}$ Incompleto & $42,9(3)$ & $57,1(4)$ & $100,0(7)$ \\
\hline
\end{tabular}

Nota: * (N) Valor absoluto referente ao percentual.

Fonte: Elaboração própria a partir dos dados disponíveis em Divulgação de Candidaturas e Contas Eleitorais do TSE.

Com relação às profissões, a Tabela 5 mostra a distribuição dos candidatos no interior dos grupos profissionais. Sejam os homens ou as mulheres, eles concentram em determinados grupos profissionais. Os homens estão mais nos grupos: Profissional da Política, Profissional Liberal, Profissional Manual, Profissional da Segurança, Funcionário Público e Aposentado, com, respectivamente, 100,0\%, 83,3\%, 76,5\%, 66,7\%, 66,7\% e 66,7\%. Já as mulheres estão mais nos grupos: Empresário Rural, Profficional da Docência, Proffisional Não Manual, Estudante e Empresário Urbano, com, respectivamente, $100,0 \%, 100,0 \%, 80,9 \%, 75,0 \%$ e 63,6\%. Profissional Manual (76,5\%, com 13 homens) e Profissional 
Não Manual (80,9\%, com 17 mulheres) foram grupos profissionais que contribuíram com o processo de recrutamento do partido ao cargo de vereança.

Tabela 5 - Distribuição do grupo profissional, segundo sexo nas eleições municipais Espírito Santo, 2016

\begin{tabular}{ccccc}
\hline \multirow{2}{*}{ Grupo profissional } & \multicolumn{2}{|c}{ Sexo } & \multirow{2}{*}{ TOTAL**** } \\
\cline { 2 - 3 } & Homem & Mulher & \\
\hline Empresário Urbano & $36,4(4)$ & $63,6(7)$ & $100,0(11)$ \\
Empresário Rural & $-* *(-)^{* * *}$ & $100,0(1)$ & $100,0(1)$ \\
Profissional Liberal & $83,3(5)$ & $16,7(1)$ & $100,0(6)$ \\
Funcionário Público & $66,7(4)$ & $33,3(2)$ & $100,0(6)$ \\
Profissional da Segurança & $66,7(4)$ & $33,3(2)$ & $100,0(6)$ \\
Profissional da Docência & $-(-)$ & $100,0(2)$ & $100,0(2)$ \\
Profissional Manual & $76,5(13)$ & $23,5(4)$ & $100,0(17)$ \\
Profissional Não Manual & $19,1(4)$ & $80,9(17)$ & $100,0(21)$ \\
Profissional da Política & $100,0(1)$ & $-(-)$ & $100,0(1)$ \\
Estudante & $25,0(1)$ & $75,0(3)$ & $100,0(4)$ \\
Aposentado & $66,7(2)$ & $33,3(1)$ & $100,0(3)$ \\
\hline
\end{tabular}

Nota: * (N) Valor absoluto referente ao percentual. ** - Valor percentual igual a 0. *** (-) Valor absoluto igual a 0. **** Valor absoluto total não corresponde a 97 (19 pessoas não declararam sua profissão). Fonte: Elaboração própria a partir dos dados disponíveis em Divulgação de Candidaturas e Contas Eleitorais do TSE.

No que tange à expansão geográfica, atualmente o PMB possui filiados em todos os Estados brasileiros. No Espírito Santo o partido conta com mais de 28 mil filiações e a Tabela 6 exibe a distribuição dos candidatos ao longo das regiões capixabas.

Tabela 6 - Distribuição da divisão regional, segundo sexo nas eleições municipais Espírito Santo, 2016 $\%(\mathrm{~N})$ *

\begin{tabular}{c|ccc}
\hline \multicolumn{3}{c}{ Sexo } & \% (N)* \\
\hline \multirow{2}{*}{ Divisão Regional** } & \multicolumn{2}{c}{ TOTAL } \\
\cline { 2 - 4 } & Homem & Mulher & \\
\hline Metropolitana & $54,8(17)$ & $45,2(14)$ & $100,0(31)$ \\
Sudoeste Serrana & $66,7(6)$ & $33,3(3)$ & $100,0(9)$ \\
\hline
\end{tabular}




\begin{tabular}{c|ccc}
\hline \multicolumn{2}{c}{ Divisão Regional** } & \multicolumn{3}{c}{ Sexo } & \% (N)* \\
\cline { 2 - 3 } & Homem & Mulher & TOTAL \\
\hline Litoral Sul & $30,8(4)$ & $69,2(9)$ & $100,0(13)$ \\
Central Sul & $50,0(6)$ & $50,0(6)$ & $100,0(12)$ \\
Caparaó & $66,7(2)$ & $33,3(1)$ & $100,0(3)$ \\
Rio Doce & $60,0(6)$ & $40,0(4)$ & $100,0(10)$ \\
Centro-Oeste & $44,5(4)$ & $55,5(5)$ & $100,0(9)$ \\
Nordeste & $20,0(2)$ & $80,0(8)$ & $100,0(10)$ \\
\hline Nota: * (N) Valor absoluto referente ao percentual ** Divisão Regional do Espírito Santo. Disponível
\end{tabular}

Nota: * (N) Valor absoluto referente ao percentual. ** Divisão Regional do Espírito Santo. Disponível em: https://is.gd/VOgVL3. Acesso em: 02 fev. 2020.

Fonte: Elaboração própria a partir dos dados disponíveis em Divulgação de Candidaturas e Contas Eleitorais do TSE.

A região Metropolitana (Cariacica, Fundão, Guarapari, Serra, Viana, Vila Velha, Vitória) foi a que mais concentrou candidatos, homens $54,8 \%$ e mulheres $45,2 \%$. Apesar do maior número de candidatos nessa região, os candidatos eleitos pertencem a outros municípios do Estado. A Tabela 6 também informa que na região Sudoeste Serrana, os homens ficaram à frente das mulheres, por outro lado, as mulheres ficaram à frente dos homens nas regiões Litoral Sul e Nordeste.

A Tabela 7 traz algumas informações sobre a experiência parlamentar, o cargo eletivo atual e a vitória eleitoral dos candidatos pelo PMB aos cargos de vereança nos municípios capixabas.

Tabela 7 - Distribuição do cargo eletivo no passado/atual, da reeleição e da vitória eleitoral, segundo sexo nas eleições municipais Espírito Santo, 2016

\begin{tabular}{|c|c|c|c|}
\hline & & & $\%(N) *$ \\
\hline \multirow{2}{*}{ Cargo eletivo no passado/atual } & \multicolumn{2}{|c|}{ Sexo } & \multirow{2}{*}{ TOTAL } \\
\hline & Homem & Mulher & \\
\hline \multirow[b]{2}{*}{ Não } & $100,0(1)$ & $-(-)$ & $100,0(1)$ \\
\hline & $47,9(46)$ & $52,1(50)$ & $100,0(96)$ \\
\hline \multirow{2}{*}{ Concorre a reeleição } & \multicolumn{2}{|c|}{ Sexo } & \multirow{2}{*}{ TOTAL } \\
\hline & Homem & Mulher & \\
\hline Sim & $100,0(1)$ & $-(-)$ & $100,0(1)$ \\
\hline
\end{tabular}




\begin{tabular}{|c|c|c|c|}
\hline \multirow{2}{*}{ Concorre a reeleição } & \multicolumn{2}{|c|}{ Sexo } & \multirow{2}{*}{ TOTAL } \\
\hline & Homem & Mulher & \\
\hline Não & $47,9(46)$ & $52.1(50)$ & $100,0(97)$ \\
\hline \multirow{2}{*}{ Vitória eleitoral } & \multicolumn{2}{|c|}{ Sexo } & \multirow{2}{*}{ TOTAL } \\
\hline & Homem & Mulher & \\
\hline Sim & $66,8(2)$ & 33,2 (1) & $100,0(3)$ \\
\hline Não & $47,9(45)$ & $52,1(49)$ & $100,0(94)$ \\
\hline
\end{tabular}

Nota: * (N) Valor absoluto referente ao percentual. ** - Valor percentual igual a 0 . *** (-) Valor absoluto igual a 0.

Fonte: Elaboração própria a partir dos dados disponíveis em Divulgação de Candidaturas e Contas Eleitorais do TSE.

No que diz respeito à experiência em cargos eletivos (Cargo eletivo no passado/atual), somente 1 candidato era vereador no momento do pleito de 2016 , os demais candidatos $(47,9 \%)$ concorreram à eleição pela primeira vez. No grupo das mulheres, todas as candidatas eram novatas na política, e, assim, elas teriam que trabalhar muito para buscar a vitória eleitoral. A mesma situação ocorre com reeleição (Concorre à reeleição), somente 1 candidato buscava a reeleição, os outros candidatos $(47,9 \%)$ participaram pela primeira vez de um disputa eleitoral. No grupo das mulheres, todas as candidatas eram iniciantes na política, e, logo, elas teriam que dedicar muito para alcançar a vitória eleitoral. Em sua primeira participação eleitoral, o PMB elegeu 3 dos seus candidatos: 2 homens e 1 mulher.

\section{CONSIDERACÕ̃ES FINAIS}

Neste artigo discutimos o perfil sociopolítico dos candidatos a vereança pelo Partido da Mulher Brasileira em terras capixabas. 0 nosso recorte temporal foi o pleito eleitoral de 2016 e a técnica de coleta e análise dos dados foram respaldadas nos principais métodos de pesquisa nas Ciências Sociais. Acreditamos que a indagação levantada na Introdução deste artigo (Quem são essas pessoas que querem defender as causas das mulheres e buscam um lugar no diminuto grupo político local?) foi respondida com as exposições e discussões dos dados coletados no site Divulgação de Candidaturas e Contas Eleitorais, vinculado ao Tribunal Superior Eleitoral.

Isto possibilitou traçar sociologicamente um pequeno perfil sociopolítico compartilhado dos candidatos do Espírito Santo que disputaram as eleições municipais de 2016 pelo Partido da MuIher Brasileira: é mulher, mas equilibrado com a presença, que também é alta, do homem; com idade entre 40 a 59 anos, faixa considerada envelhecida para quem deseja entrar no mundo da política; casado, que não ofereceu nenhum espanto; possui o ensino médio completo, mas alguns 
possuem uma graduação completa; é funcionário público e também profissional liberal; sem experiência qualquer no mundo da política.

Mesmo em uma época em que o Brasil possui um eleitorado majoritariamente feminino, a participação das mulheres ainda é ínfima em todas as instâncias políticas. Percebe-se claramente que a sub-representação feminina nessa arena além de ainda receber os reflexos da influência cultural negativa da ideologia da elite patriarcal, sofre também com a frágil estrutura político partidária, pois apesar da grande maioria das legendas discursarem e apoiarem a igualdade entre os sexos na política, o discurso não se efetiva na prática e a trajetória da mulher brasileira nessa esfera continua sendo marcada pela discriminação.

O Partido da Mulher Brasileira surge nesse cenário com a proposta de fazer a diferença e promover a igualdade na participação, construindo a identidade política da mulher sem atentar contra a identidade masculina, desmistificando a ideia de superioridade de um sobre o outro. Apesar do nome guardar total relação com representatividade feminina, praticamente metade dos candidatos que a representaram foram homens e em sua primeira eleição.

\section{REFERÊNCIAS}

KELLER, Suzanne. 0 destino das elites. Rio de Janeiro: Forense, 1967.

CEVA, Antonia; SCHUMAHER, Schuma. Mulheres no poder: trajetórias na política a partir da luta das sufragistas do Brasil. Rio de Janeiro: Editora Edições de Janeiro. 2015.

FREITAS, Necilene Almeida; FELISBINO, Riberti Almeida; SANTIAGO, Danilo Roberto Pereira. Da cozinha ao palanque: a baixa representatividade feminina na política e o Partido da Mulher Brasileira nas eleições capixabas de 2016. Curitiba: CRV, 2018.

INTER-PARLIAMENTARY UNION. Women in national parliaments. Disponível em: http://www.ipu. org/wmn-e/arc/classif011116.htm. Acesso em: 2 fev. 2020.

MOISÉS, José Alvaro; SANCHEZ, Beatriz Rodrigues. Representação política das mulheres e qualidade da democracia: o caso do Brasil. In: $\mathbf{O}$ Congresso Nacional, os partidos políticos e o sistema de integridade: representação, participação e controle institucional no Brasil contemporâneo. Rio de Janeiro: Konrad-Adenauer-Stiftung, 2014.

PERISSINOTTO, Renato. As elites políticas: questões de teoria e método. Curitiba: Editora Intersaberes, 2012.

VERUCCI, Florisa. 0 direito da mulher em mutação: os desafios da igualdade. Belo Horizonte: EditoraDel Rey, 1999. 
1 Mestre em Sociologia Política pela Universidade Vila Velha e assessora em assuntos na área do Direito.

E-mail: necilene.almeida@gmail.com

2 Mestre em Segurança Pública pela Universidade Vila Velha e assessora em assuntos na área do Direito.

E-mail: erikaocavalcanti@hotmail.com

3 Doutor em Ciências Sociais pela Universidade Federal de São Carlos; Professor de cursos de educação profissional do CEET Vasco Coutinho, Vila Velha/ES.

E-mail: ribertialmeida@tutanota.com

\section{(@) (1) (-)}

Este artigo é licenciado na modalidade acesso abertosob a Atribuição-Compartilhalgual CC BY-SA

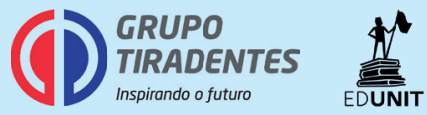

